\title{
Real Levelized Cost of Energy with Indirect Costs and Market Value of Variable Renewables: A Study of the Korean Power Market
}

\author{
Sung-Hyun Hwang, Mun-Kyeom Kim * and Ho-Sung Ryu \\ Department of Energy System Engineering, Chung-Ang University, 84 Heukseok-ro, Dongjak-gu, \\ Seoul 06974, Korea \\ * Correspondence: mkim@cau.ac.kr; Tel.: +82-2-820-5271
}

Received: 9 May 2019; Accepted: 24 June 2019; Published: 26 June 2019

\begin{abstract}
A levelized cost of energy ( $L C O E)$ is a methodology for comparing power generation costs in the transition to renewable energy $(R E)$. However, the major limitation of evaluating $R E$ based on the $L C O E$ is that it does not consider indirect costs, such as the environmental and curtailment effect. This paper proposes the real $L C O E$ ( $r L C O E$ ) approach that accounts for indirect and direct generation costs. The mathematical approach to estimating indirect costs is derived from economic theory. The indirect effects, which quantify all benefits generated due to RE, is related to the variability of the share $R E$ in the energy generation mix. The rLCOE enhances the accuracy of the economic comparison of power generation costs and the derivation of the optimal quantities of $R E$ because external effects are incorporated into the $L C O E$ principles. This approach has taken into account electricity demand, fuel prices, and environmental costs for each energy source to adequately compare generation costs. Simulations have been performed to demonstrate the application of the rLCOE approach in the Korean power market. Here, the unit variation of costs with the $R E$ share were analyzed. The results show that indirect cost savings of an additional unit of $R E$ begin to fall in scenario 3 in contrast to the result of $L C O E$ approach indicating higher generation costs with $R E$ share, especially, the proportion of $R E$ in the generation mix is higher than $20 \%$. Thus, the optimal power generation can be evaluated using the $r L C O E$ approach.
\end{abstract}

Keywords: real LCOE; indirect costs; renewable energy; market value; social welfare

\section{Introduction}

\subsection{Background and Literature Review}

The world is facing substantial environmental and energy challenges, one-third of the world's population still does not have access to electricity, and that some developing countries have a plan to use fossil fuels as the major source of energy. Although this trend has existed, an economical and environmental source of electricity is required to fulfill the environmental regulation. However, there are some challenges with the feasibility of electricity generation from different sources, particularly as renewable energy $(R E)$ is added to the grid. What is the real cost of transitioning to renewable energy? What is the optimal power mix for accommodating $R E$ into the power grid efficiently?

To respond to these questions, various methodologies have been proposed to calculate the optimal $R E$ share regarding low-carbon emissions [1-5]. Specifically, these studies have been conducted in terms of integrative and distributive generation planning. Reference [1] proposed the integration for distributed generation approach and determined an optimal investment plan to fulfill physical, economic, and operational constraints. In Reference [2], an integrated planning approach was also addressed and the probabilistic distribution was used for calculating the carbon footprint of distribution 
systems that included both direct and indirect emissions. Especially, reference [3] used an active-reactive optimal power flow containing carbon footprint allocation while considering transmission losses. In References [4,5], the carbon emission flow model that was introduced helps to clearly allocate carbon emission mitigation among different energy sources. However, these research approaches focused on single or hybrid systems, thus limiting their ability to consider the indirect effects of power systems as an economic principle.

On the other hand, levelized cost of energy ( $L C O E)$ is widely used as a methodological approach capable of comparing the profitability of different power sources while also calculating the optimal $R E$ share. Policy makers in particular use LCOE to estimate and respond to the above-mentioned questions. The $L C O E$ represents the cost of the entire life cycle per unit of power generation. Thus, it enables the comparison of generation costs of $R E$ and non-renewable energy (NRE) [6]. RE sources show high fixed costs and low variable costs, while $N R E$ sources have different fixed-to-variable-cost ratios. When the LCOE of $R E$ is lower than that of $N R E$, it is conducive to the deployment of $R E$, and its penetration rate is accelerated [7].

There have been extensive studies on the use of LCOE in the electricity market. The effect of the variability of $R E$ on system integration cost was analyzed in Reference [8]. Here, the author emphasized that the LCOE cannot demonstrate the economics of RE. In Reference [9], the electricity generation should respond to variable demand and cannot maintain uniform quality due to its variability. Therefore, the amount of electricity generated by $R E$ can be different each time. Since the amount of $R E$ generation is determined by an externality such as wind and solar density, the LCOE represents a variable value [10]. However, the LCOE neglects the temporal variability of electricity [11].

More recently, some important pioneering works have developed an effective economic approach to determining the LCOE [12-15]. An extended LCOE that applies economic theory has been utilized to evaluate power generation costs in [12]. Here, if the $L C O E$ of $R E$ is equal to the marginal economic value, it can be considered economically efficient under the conditions of a perfect market. In [13], the marginal system $L C O E$ was proposed to formalize the arguably vague concept of integration costs. Here, the integration cost in terms of marginal $L C O E$ has been estimated for RE penetration levels as high as $60 \%[13,14]$. Furthermore, in [15], results indicated the same economic effect was achieved, assuming a perfect market where the marginal cost is equal to the market value. However, the above works did not evaluate indirect effects including environmental costs and the curtailment effect, as based on economic theory. Therefore, it is recommended that future studies continue to operationalize and measure the indirect effects of $R E$.

Meanwhile, other recent studies have considered a social value of the power market. In Reference [16], the economic assessment could account for both the cost and the social value of the technology. Social value became integral to understanding the representation of risk in the large wind power industry. This paper inspired critical costs modeling for wind energy projects including market risk mitigation strategies that included a review of social impacts. Especially, in [17], the authors recognize that indirect effects could cause market distortion and noted that it is difficult to assess indirect effects because a chain of cross-market price effects is involved. At the same time, the magnitudes, types, and interactions of economic distortions can also affect their size. That is the reason why many empirical results acknowledge the existence of indirect effects as a special case. For example, a decline in the share of $R E$ in California as a result of market distortion effects was identified by [18,19]. Namely, the economic value of wind power is significantly reduced when the wind share increases from $0 \%$ to $60 \%$. The authors proved the difficulty of comparing the LCOE of RE sources accurately. Thus, our research assumes a perfect market to reflect the economics of $R E$ and evaluates external costs from an economic perspective. It reinforces the necessity of an improved approach to evaluating $R E$ sources. Finally, our research conducted an in-depth analysis of power market factors including an indirect effect replacing NRE with $R E$ penetration levels. 


\subsection{Contribution and Paper Organization}

Our research proposes a new $r L C O E$ approach that includes all of the economic, social, and indirect costs associated with $R E$. While based on the $L C O E$ principle, this approach also reflects indirect effects. There is no unified definition for indirect costs in economic theory [20]. Thus, continued efforts are required in order to expand an effective approach for the estimation of indirect costs that are related to the economics of RE. Consequently, our work shows the mathematical expression for overall cost based on economic theory, so that the rLCOE is constructed as the sum of the generation costs including total indirect costs. The main purpose of $r L C O E$ is to evaluate $R E$ and NRE more efficiently. In fact, our approach can also reflect the market perspective. In summary, the main contributions of this work are categorized as follows:

(1) The evaluation of power generation costs using the $L C O E$ is constructed to be applicable to the comparison of generation sources. The rLCOE is intuitive and incorporates existing LCOE principles while expanding it to reflect external costs.

(2) The rLCOE is linked to the economic concept of the market value, in contrast, the LCOE is only based on and limited to the current operation of the power system. More importantly, the estimation of the cost of the power system considers both direct and indirect effects; both are related to economic theory.

(3) The indirect effect is related to the variability of $R E$. It can be quantified in terms of all benefits generated due to RE using the rLCOE approach.

(4) It can explain the most important factors affecting the unit generation cost while analyzing the effect of the RE share through $r L C O E$.

(5) All social welfare $(S W)$ measures that incorporate the indirect effects from the $R E$ share can be calculated, and differences from the existing methodology can be presented.

Unlike the existing $L C O E$ approach, the rLCOE can account for indirect costs and directly calculate the costs incurred from $R E$. For example, the electricity price reflects the marginal cost and estimates the total cost derived from the current market environment. The rLCOE and indirect costs are derived as a quantitative expression, which can be applied to estimate market costs. The indirect costs of high $R E$ shares can be evaluated as a range of costs with variability in accordance with fuel costs. Although indirect costs can be varied with growing $R E$ shares, it can also present an economic barrier in terms of the expansion of the proportion of $R E$ in the power generation mix.

This paper is organized as follows: In Section 2, the rLCOE is conceptually defined and quantified using a mathematical formulation that reflects economic formulas. In Section 3, we conceptualize the correlation between $r L C O E$ and market value. Section 4 presents the methodology to estimate the changes in market values caused by changes in several key factors including demand and fuel costs. In Section 5, the methodology is applied to the Korean power market to evaluate the impact of RE on the grid in terms of market value, and conclusions are drawn in Section 6.

\section{2. rLCOE Analysis}

The $L C O E$ is commonly applied to compare different power generation. The $L C O E$ is expressed in terms of the unit cost $(\$ / \mathrm{kWh})$ of electricity generation when the present value of expected profits from electricity sales is equivalent to the present value of all expected costs during the lifecycle [8]. The LCOE has several improvements as a cost metric, such as its ability to standardize costs into an easily comprehensible format across technology types [21]. Ultimately, it has become the standard formulation for cost comparisons and is applied by public authorities and many other stakeholders. Although it is widely used, the LCOE only examines the factors affecting the total direct costs of generating electricity, which cannot include indirect costs like environmental effects [22]. For that reason, previous research emphasizes that both direct and indirect costs should be considered to overcome the limitation of the LCOE [23]. In addition, recent studies of indirect costs of power generation have estimated different cost components using a bottom up approach. Namely, "air pollutant costs", "water pollutant 
costs", "human impact costs", and "system costs" have been examined [12,24]. It is assumed that these components add up to total indirect costs, even though it is hard to consider all components.

For solving these problems, in our work, total environmental costs and indirect benefits are derived using a top-down approach. The rLCOE calculation is formulated as Equation (1) for including the direct and indirect plant costs as follows:

$$
r L C O E=\frac{\sum \frac{I C+O C}{(1+r)^{n}}}{\sum \frac{A P}{(1+r)^{n}}}+\Delta,
$$

where $n$ is the lifetime of the plant; IC is the initial investment costs, $O C$ is the O\&M (operating and maintenance) costs, $A P$ represent the annual energy production at year $t ; r$ means the discount rate; and $\Delta$ indicates the indirect costs. The indirect $\operatorname{costs} \Delta$ is given by:

$$
\Delta=\frac{d}{d E_{R E}} C_{N R E}
$$

Equation (2) denotes the marginal indirect benefit including the environmental cost of increasing $R E$ capacity instead of NRE. It is to be noted that opportunity costs are a form of indirect costs. Here, $\Delta$ represents marginal indirect benefit when the $N R E$ is escalated as $C_{N R E}$, cost of $N R E$, while a $R E$ generation $E_{R E}$ is varied. Thus, the simplified $r L C O E$ can be calculated as:

$$
r L C O E=L C O E+\Delta .
$$

However, it is difficult to determine the indirect benefit when $R E$ are added to the power market. Therefore, our research tried to formalize the rLCOE so that it was in line with Equation (3). We defined that the opportunity costs of a power source were all additional costs of NRE when $R E$ was introduced. Since indirect costs cannot be measured or estimated directly, instead, a single system, with and without $R E$, need to be compared to identify additional indirect costs. For the $R E$ case, the annual power demand $E_{t}$ in an electricity market is given by:

$$
E_{t}=E_{N R E}+E_{R E}
$$

where $E_{N R E}$ denotes NRE electricity generation, $E_{t}$ is total electricity generation, and $E_{R E}$ is $R E$ generation. $E_{t}$ is partly supplied by $E_{R E}$. The resulting $E_{N R E}$ needs to be provided by dispatchable power plants.

Referring to Equation (4), $E_{t}$ is partly supplied by $R E$ and $N R E$ and total costs can be formulated as:

$$
\begin{gathered}
C_{t}=C_{N R E}-C_{R E}, \\
C_{R E}=\frac{E_{N R E}}{E_{t}} C_{t}(0) .
\end{gathered}
$$

Here, $C_{t}$ is the total cost, divided into the generation costs of $R E$ and all other costs for NRE, $C_{t}(0)$ is the average costs in a system without NRE. Since indirect costs of RE are designated as not being part of generation costs of $R E$, they can emerge from comparing the $C_{N R E}$ with and without $R E$. Unfortunately, the absolute difference of the costs can contain direct and indirect costs. Thus, it is important to define the specific costs per unit of NRE. This reconciles the problem of different values of NRE and RE. In Equation (6), indirect costs can stand for the difference of specific costs in the $N R E$ system increased by $E_{N R E}$ when $R E$ generation is volatile. The specific indirect costs $C_{N R E} / E_{N R E}$ typically increase without $R E$. 
Equation (6) comprises the additional costs in the NRE when introducing RE. The rLCOE can be evaluated with any power energy mix and it can estimate indirect costs comparing cases with and without RE.

\section{Evaluation of Social Welfare Using rLCOE}

The $r L C O E$ can be expressed as the marginal cost of an additional $R E$.

$$
\begin{gathered}
C_{t} \rightarrow \text { min }, \\
\frac{d}{d E_{R E}} C_{t}=0 .
\end{gathered}
$$

In Equations (7) and (8), the cost-optimal deployment of $R E$ is reached. This occurs when the total costs of a power mix are minimal when the share of $R E$ varies. According to Equations (6)-(8), the total costs can be expressed as:

$$
C_{t}=C_{R E}+C_{N R E}-\frac{E_{t}}{E_{R E}} C_{t}(0)
$$

Inserting this into the optimal Equation (9) indicates:

$$
\frac{d}{d E_{R E}} C_{t}=\frac{d}{d E_{R E}} C_{R E}+\frac{d}{d E_{R E}} C_{N R E}-\frac{1}{d E_{R E}} \frac{d}{d E_{R E}} C_{t}(0) .
$$

In Equation (10), the interpretation of these terms gives the meaning for the evaluation of $R E$. The first summand is the marginal generation costs of $R E$ expressed by $r L C O E_{R E}$ and the second summand is the marginal indirect costs of NRE. The third summand is equal to 0 when $R E$ is not present. Note that NRE creates indirect costs that have to be included in total costs $C_{t}$. Accordingly, the third summand equals the average indirect costs of the system as follows:

$$
0=r L C O E_{R E}+r L C O E_{N R E}-\frac{1}{E_{t}} C_{t}(0) .
$$

Using Equation (11), the optimal condition is evaluated as follows:

$$
\begin{gathered}
\frac{C_{t}(0)}{E_{t}}=r L C O E_{R E}+r L C O E_{N R E}, \\
r L C O E_{R E}=-r L C O E_{N R E} .
\end{gathered}
$$

It can be seen from Equations (12) and (13) that the optimal deployment of $R E$ is given by the point where the absolute value of $r L C O E_{R E}$ is equal to the $r L C O E_{N R E}$. In Equation (13), the left-hand side can be explained as the marginal economic costs of $R E$, while the right-hand side can be seen as the value of $R E$ because it represents the opportunity cost of covering power demand with NRE generation. In other words, $R E$ deployment is optimal where the marginal economic costs of $R E$ meet with their value, which is in line with economic theory.

Figure 1 illustrates the rLCOE approach depending on RE and NRE deployment. Firstly, Figure 1a depicts the correlation between $r L C O E$ and RE deployment whereby indirect costs increase with higher $R E$ deployment and can be negative, in particular if the penetration of $R E$ is low. Figure $1 \mathrm{~b}$ shows the relationships between $r L C O E$ and market value when $R E$ deployment varies. Here, the intersection of increasing $r L C O E$ of $R E$ and average costs in NRE gives an optimal quantity expressed as $E^{*}$. By adding indirect costs to $L C O E, r L C O E$ can be used to derive the optimal share of $R E$ in the power generation market. In order to account for indirect costs and the market value of $R E$, an equivalent perspective can be explained as the marginal cost savings in the NRE when increasing the $R E$ deployment. According to [25], SW is related with the quality of life that includes factors such as the condition of 
the environment (air, soil, water) and essential social services. In general, an increase in $S W$ results in a decrease in social costs [26].

$$
S W=\frac{d}{d E_{R E}} C_{N R E}
$$

Equation (14) assumes marginal indirect costs, which can be explained as the cutback of the market value equal to $S W$. It can be compared to the average costs of NRE that correspond with the annual electricity price in a perfect market. The reduction of the market value is not only driven by the variability of $R E$, but can also be interpreted as the economic costs of variability. Inserting Equation (2) into (14), the optimal condition Equations (15) and (16) can be rephrased as follows:

$$
\begin{gathered}
\Delta=\frac{d}{d E_{R E}} C_{N R E}=\frac{C_{t}(0)}{E_{t}}-S W, \\
-\Delta=S W .
\end{gathered}
$$

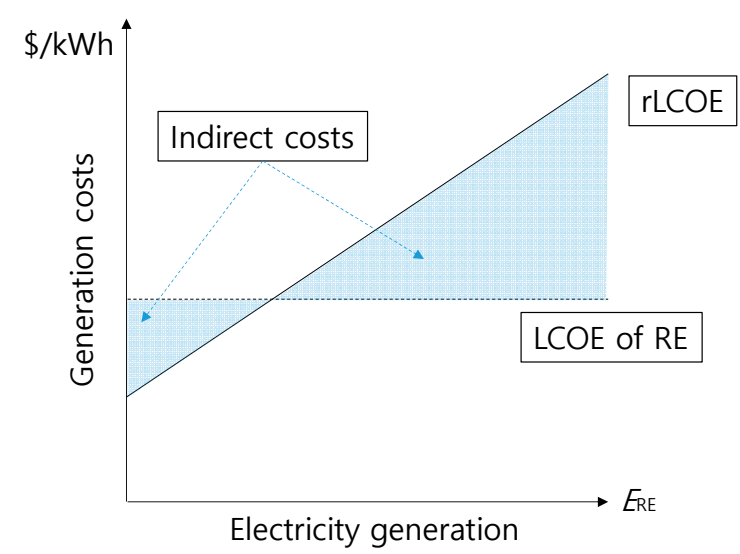

(a)

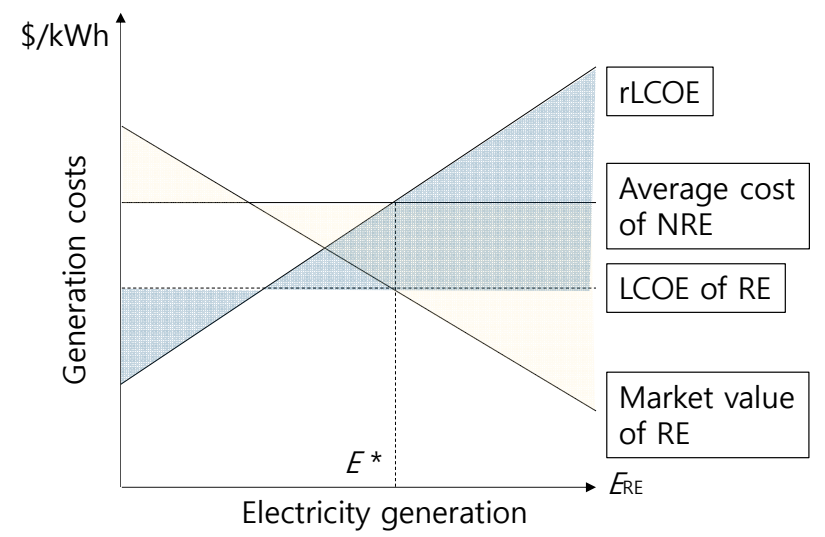

(b)

Figure 1. The principle of $r L C O E$ with optimal RE deployment. (a) Relationship with $r L C O E$ and RE deployment. (b) Correlation with rLCOE and market value. 
The market value decreases with $R E$ penetration. The optimal deployment of $R E$ is given by the point where the market value of $R E$ equals their marginal generation costs. To sum up, the methodology of accounting for indirect costs leads to the derivation of optimal levels of power generation from $R E$. It measures all the quantitative impacts of the variable power mix. In addition, it can calculate indirect costs expressed as market value. The market value of $R E$ has the opposite effect to costs, which might be induced, in particular, during hours of high $R E$ supply $[19,27]$. Since it is noted that the market value can be obtained from actual prices, it allows the quantification of indirect costs from market prices, if markets can be assumed to be perfect.

\section{Estimation of Indirect Costs}

\subsection{Sensitivity Analysis}

The Korean power market has been operated as a cost-based pool [28]. The market price is not only determined by the fuel cost, but because $R E$ has a very low marginal cost, it can reduce the price of power. In this research, variation of the fuel costs, and variation of the electricity demand can be regarded as significant parameters for the sensitivity analysis.

Sensitivity analysis considers the level of uncertainty of the output that can be evaluated in terms of different sources of uncertainty in its inputs. Sensitivity analysis can be conducted using three different approaches: (i) Mathematical; (ii) statistical; and (iii) graphical [29]. The mathematical method assesses the sensitivity of a result to the change of an input using multiple input values. The statistical method involves conducting simulations in which inputs are set probability distributions and the variance in inputs is assessed based on the output distribution. The graphical method gives a representation of the sensitivity of outputs with respect to input changes in the form of graphs and charts. Mathematical sensitivity analysis will be conducted in our work. Although it does not address the variance in the output with respect to the volatility in the inputs, it can assess the effect of variation in screening important inputs. In addition, this method can be used for verification, and to distinguish inputs that requisite more advanced research. The mathematical sensitivity analysis is given by:

$$
\text { Sensitiviy_value }=\frac{\partial}{\partial E_{t} \partial F C} r L C O E,
$$

where $F C$ denotes fuel costs, and $E_{t}$ is equal to total power demand.

\subsection{Procedure of Proposed rLCOE Approach}

The flowchart shown in Figure 2 illustrates our rLCOE analysis. SW can be obtained to determine the optimal RE mix in each scenario. The procedure for simulation is as follows:

Step 1: Initialize inputs and generate the scenario.

(1) Start with an initialization of inputs, which include CAPEX, OC, and the capacity factor.

(2) Generate a scenario based on the portion of $R E$ capacity.

(3) Formulate total $r L C O E$ with indirect factors. Total indirect cost will change according to each scenario.

Step 2: Evaluate $S W$ by solving the $r L C O E$ given in each scenario.

It is based on the result from $r L C O E$. Note that it can be checked whether the overall indirect cost of the power market is within the defined limits. If not, the $r L C O E$ is infeasible. The scenario should be repaired, and step 2 can be repeated.

Step 3: Compare the rLCOE.

Each scenario is solved for $r L C O E$ to obtain the figure for $S W$, which leads to the lowest total cost including indirect costs. After that, the sensitivity analysis can be conducted and the optimal $R E$ mix comparing the scenario results can be printed and the procedure is finished. 


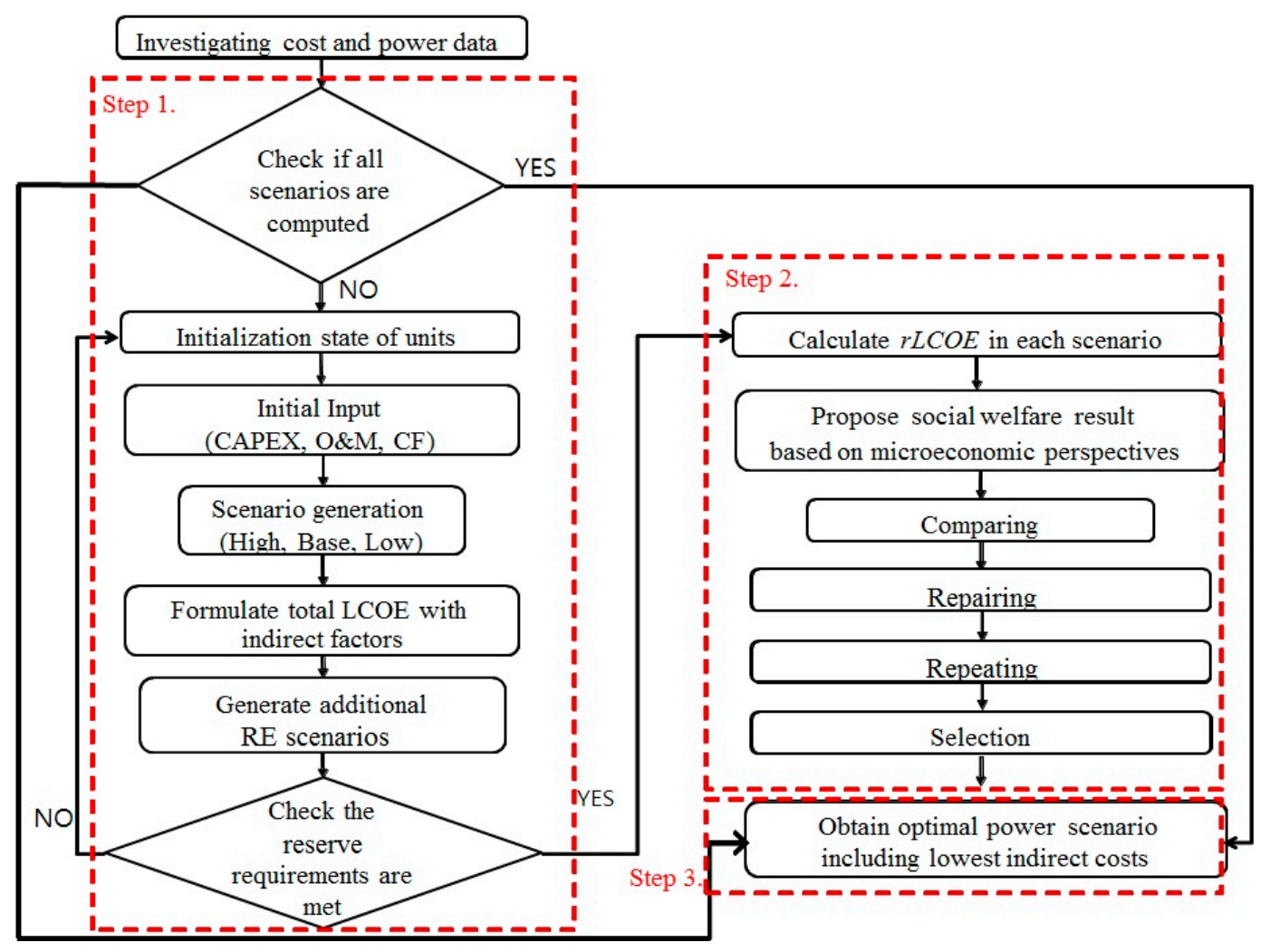

Figure 2. Proposed process of the rLCOE approach.

\section{Case Study}

\subsection{Data Description and Scenario Assumptions}

The market price of power is determined by a number of different factors such as demand, power mix, fuel, $\mathrm{CO}_{2}$ price, and $R E$ penetration. Since the future values of these factors can be determined by a policy framework at the country level, it is important to generate scenarios that appropriately follow government policy. In our work, the demand and the installed power capacity have been used in the $8^{\text {th }}$ power supply plan in Korea [30]. Since this plan includes a target level of power capacity, generation mixes, and subsidy programs for the next 14 years (2018-2031), they are considered using the proposed $r L C O E$ approach. Figure 3 shows the example of the power supply plan representing the average annual electricity demand with the growth rate. The growth of electricity demand is assumed to be $2.1 \%$, which indicates that electricity demand has entered a low growth phase. The $R E$ generation capacity in the power supply plan follows the $R E$ target. Our study sets the proportion of $R E$ with reference to the $R E 3020$ plan [31]. It assumes an increasing share of $R E$ penetration in Korea, for instance, the total $R E$ share in the generation mix rises to $20 \%$ by 2030 . The variability of $R E$ is also considered in this work. The data of yearly power generation profiles for $R E$ are taken from the Korean Power Exchange [32]. In order to evaluate the effect of increasing RE generation to market price, our study took into account the historical average variations of $R E$ utilization. 


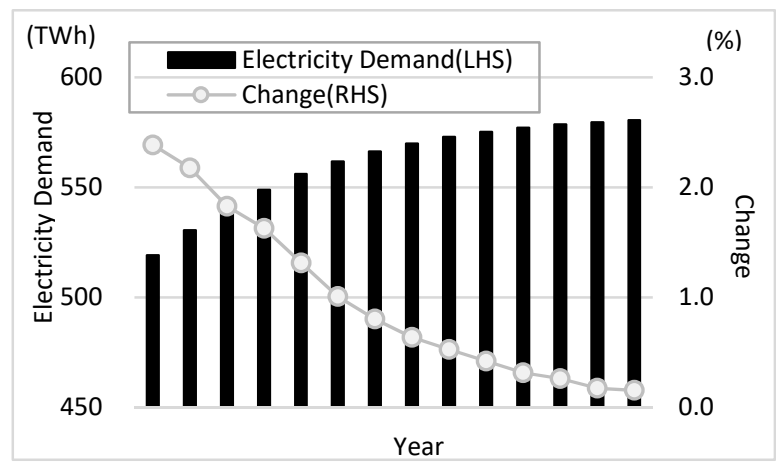

Figure 3. Electricity demand and growth rate for rLCOE in Korea.

In Korea, the market price is determined by the marginal cost of the power plant [33], and then it can be linked to the international crude oil price. Since Asian LNG (Liquefied Natural Gas) is usually contracted from the Middle East, this contract type is mainly based on the crude oil price [34]. In our work, fuel costs are applied using assumptions based on IEA (International Energy Association) forecasts. Figure 4 shows the crude oil and gas price forecasts of the World Energy Outlook released by IEA [35]. The IEA data shows that crude oil prices rise to $\$ 124 / \mathrm{bbl}$. by 2040 , and LNG prices go up to $\$ 12.4 / \mathrm{mmBTU}$.

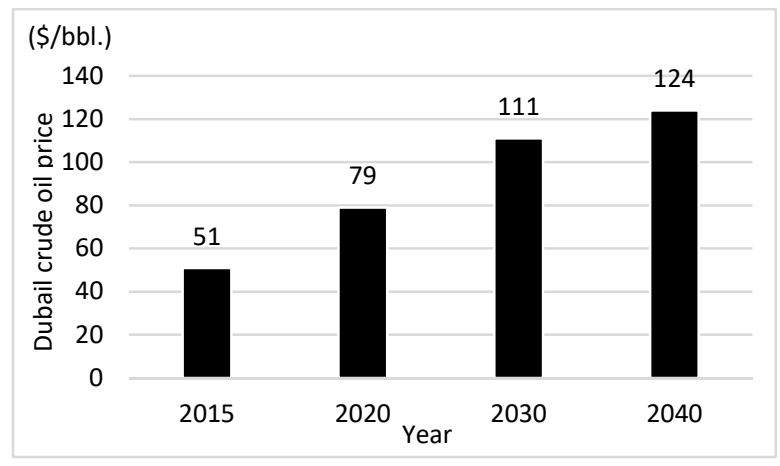

(a)

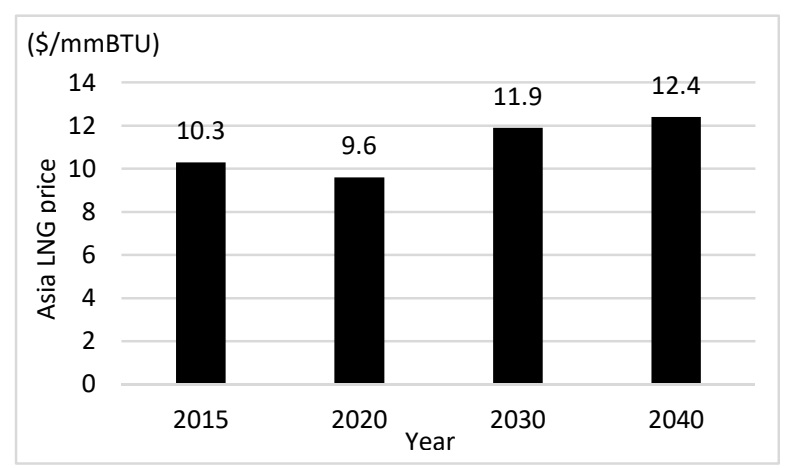

(b)

Figure 4. IEA market price projection. (a) Crude oil price; (b) Asian LNG price.

The annualized total costs can be also computed for the proposed approach. Table 1 depicts the cost parameter of the energy source. It shows the fixed costs of each energy source and indicates other parameters used to compute the annualized costs. The annualized costs, which are inputs to the model, are used from cost estimates of the initial investment costs and fixed operational and maintenance 
costs. The interest rate is assumed to be $5 \%$. The variable costs are computed from the cost estimates of the variable O\&M and fuel costs.

Table 1. Adapted cost parameters of the energy source for $r L C O E$ from [36].

\begin{tabular}{ccccc}
\hline Energy Source & IC $^{\mathbf{1}} \mathbf{( \$ / k W )}$ & VOC $^{\mathbf{2}} \mathbf{( \$ / M W h )}$ & FOC $^{\mathbf{3}} \mathbf{( \$ / \mathbf { k } / \mathbf { y r } )}$ & FC $^{\mathbf{4}} \mathbf{( \$ \mathbf { M W h } )}$ \\
\hline Gas & 760 & 0.8 & 50 & 30 \\
Coal & 1400 & 0.0 & 80 & 8 \\
Nuclear & 5100 & 0.0 & 160 & 8 \\
Wind & 1400 & 0.0 & 44 & 0 \\
Solar & 600 & 0.0 & 19 & 0 \\
\hline \multicolumn{2}{c}{${ }^{1}$ Initial investment costs, ${ }^{2}$ variable O\&M costs, ${ }^{3}$ fixed O\&M costs, and ${ }^{4}$ fuel costs. }
\end{tabular}

Table 2 indicates the emission pollutants factors of the energy sources representing marginal damages. These data were used to calculate the total indirect costs. It determines the emission quantity and pollutant costs for $r L C O E$. Certainly, coal and crude oil have high $\mathrm{CO}_{2}$ emission factors; gas generates fewer emissions than other fossil fuels.

Emission costs are calculated by the average emission factor, which refers to the unit power plant energy consumption in power plants and the amount of emissions of $\mathrm{CO}_{2}, \mathrm{SO}_{\mathrm{x}}, \mathrm{NO}_{\mathrm{x}}$, and fine dust. Total emissions are multiplied by the unit's fuel consumption, net calorific value of fuel, and emission factors, and are then divided by the total electricity consumed. The calculation Equation (18) is as follows:

$$
f_{x}=\frac{M_{x}}{Q}=\frac{F_{i} \times N V C_{i} \times M_{x i}}{Q}
$$

where $M_{x}$ denotes total emissions of $x(i), Q$ is the total electricity generation (MWh), $F_{i}$ is the fuel consumption of a unit $i$ (unit of mass or volume), and $N V C_{i}$ is the net calorific value of fuel $i$ (energy content, GJ/unit of mass or volume). In general, prior research has calculated the quantity of pollutants emitted using power plant and unit costs taken from descriptive statistics of the data set in [37-39]. The marginal costs of pollutants in Table 2 were maintained from prior literature. Although we used the existing data set, we focused on developing a methodology derived from economic theory showing mathematical expressions for estimating indirect costs.

Table 2. Pollutant generation and cost from various generation plants for $1 \mathrm{GW} /$ year [37].

\begin{tabular}{ccc}
\hline Energy Source & Quantity (Ton) & Cost (USD) \\
\hline Crude oil & $\mathrm{CO}_{2}$ & $5,000,000$ \\
& $\mathrm{SO}_{2}$ & 40,000 \\
& $\mathrm{NO}_{\mathrm{x}}$ & 25,000 \\
Coal & Fine dust & 25,000 \\
& $\mathrm{CO}_{2}$ & $6,000,000$ \\
& $\mathrm{SO}_{2}$ & 120,000 \\
& $\mathrm{NO}_{\mathrm{x}}$ & 25,000 \\
Gas & Fine dust & 300,000 \\
& $\mathrm{CO}_{2}$ & $3,000,000$ \\
& $\mathrm{SO}_{2}$ & 20 \\
& $\mathrm{NO}_{\mathrm{x}}$ & 13,000 \\
\hline
\end{tabular}

In order to verify the proposed approach, Table 3 shows $R E$ capacity and generation in each scenario. Scenario 1 was the base case so that the indirect costs of $R E$ capacity could be determined using the base case as a reference. In scenario 1, RE capacity was assumed to increase to $20 \%$ of total consumption according to RE 3020 plan [40]. Scenario 2 was the low case including $24 \mathrm{GW}$ of additional $R E$ capacity until 2030, resulting in 13\% RE share of total consumption. By comparing scenario 1 with scenario 2, the indirect cost of $R E$ penetration at a low level in Korea could be computed. Finally, scenario 
3 represented the high case of $R E$ generation equal to $51 \%$ of total consumption. The comparison of this scenario with scenario 1 indicated the indirect costs of $R E$ at this level of penetration.

Table 3. RE capacity and generation in each scenario.

\begin{tabular}{cccccc}
\hline Year & $\mathbf{2 0 1 8}$ & $\mathbf{2 0 2 2}$ & $\mathbf{2 0 2 6}$ & $\mathbf{2 0 3 0}$ & $\mathbf{2 0 3 1}$ \\
\hline Electricity generation (TWh) & 34.4 & 116.6 & 179.0 & 251.6 & 252.0 \\
RE Capacity (GW) & 11.3 & 23.3 & 38.8 & 58.5 & 58.6 \\
Electricity generation (TWh) & 34.4 & 86.6 & 115.6 & 150.1 & 150.3 \\
RE Capacity (GW) & 11.3 & 17.3 & 25.1 & 34.9 & 35.0 \\
Electricity generation (TWh) & 34.4 & 176.7 & 305.9 & 454.6 & 455.4 \\
RE Capacity (GW) & 11.3 & 35.3 & 66.3 & 105.7 & 105.9 \\
\hline
\end{tabular}

\subsection{Simulation Results}

\subsubsection{Impact of RE on the Grid}

The Korean electricity market is operated as a cost-based pool. Since $R E$ sources have very low marginal cost, which means low variable $F C$, it is dispatched first and thereby, reduces the demand for NRE sources. If power demand decreases, a power plant with a lower marginal cost can determine the market electricity price. Due to this principle, the larger the proportion of $R E$ installed, the lower the electricity market price can be expected in day-ahead power market. Figure 5 illustrates the total power capacity and generation for the electricity demand with increasing shares of variable renewables in electricity generation. Since the total capacity of base load plants was defined, the utilization rate of $N R E$ could be varied according to the reduction in power demand produced by $R E$. As shown in Figure 5a, the capacity of NRE was volatile in the cost-based pool, varying between $37 \%-51 \%$. This can be explained by the relatively higher fuel price, which means NRE was not utilized, as well as the availability of sufficient flexibility due to existing NRE generation. In Figure $5 c$, especially, as the proportion of $R E$ in total consumption rose to $51 \%$, the dispatchable generations were curtailed significantly. As a result, the share of coal generation decreases from $67 \%$ (Scenario 1 ) to $26 \%$ (Scenario 3). The share of gas in total generation also decreased from $13 \%$ (Scenario 2) to $0 \%$ (Scenario 1-3). Although the total dispatchable capacity was decreased in the day-ahead market, the total reduction of demand could be regarded as low compared to the increase in $R E$ capacity. This was because the low contribution of $R E$ generation to accommodate peak load results in only a slight reduction in total capacity required for the NRE, whereas the capacity factors of generators decreased significantly as a utilization effect. Additional $R E$ capacity in scenarios 1 to 3 increased the impact of demand curtailment when the $R E$ utilization was stable as shown in Figure $5 \mathrm{~d}$. Consequently, the increase of $R E$ capacity amplified the effect of decreasing electricity demand. The investments and total dispatchable capacity for the NRE on the day-ahead market could be decreased.

Figure 6 shows the simulation results of generation costs including the initial investment cost, variable O\&M cost, and fixed O\&M cost of total power source with increasing $R E$ shares. The investment cost of $R E$ was assumed to be $\$ 1400 / \mathrm{kW}$, in line with currently realized costs [37]. In case of lower $R E$ capacity, the total $O C$ and $F C$ were in the range of $\$ 19-24 / \mathrm{MWh}$ and $\$ 3-18 / \mathrm{MWh}$ for $21 \%-59 \% R E$ shares. The largest part of these costs comes from $O C$, which increased with increasing $R E$ penetration. The $F C$ decreased with increasing shares of $R E$. As shown in Figure $6 \mathrm{~b}$, an interesting finding was that the fuel cost of total generation decreased by $64 \%$ when a $59 \%$ increase in share of $R E$ generation occurred. The additional $R E$ capacity allowed peak demand to be reduced when NRE generation was low. Thereby, the total power capacity required a decline on the day-ahead market. This reduced the variable and indirect costs significantly by $50 \%-74 \%$. However, the IC of the $R E$ investments was higher than the total reduction of $F C$. Therefore, most of the net benefit of $R E$ investments for reducing the total environmental and variable cost of $R E$ was computed from the reduction of $F C$. It can be noted that the measure of the decrease in costs depends on the relative availability of $R E$ generation capacity. 


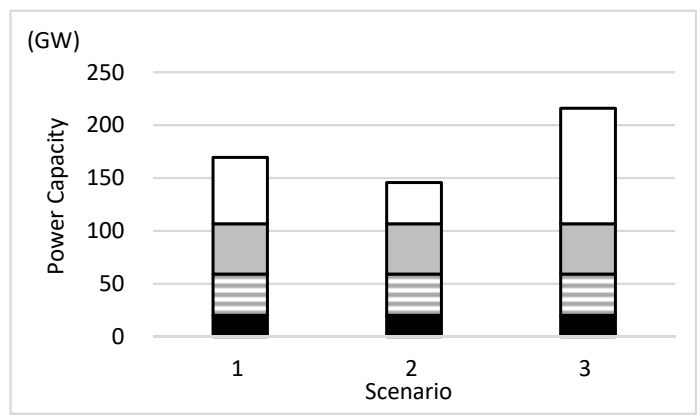

(a)

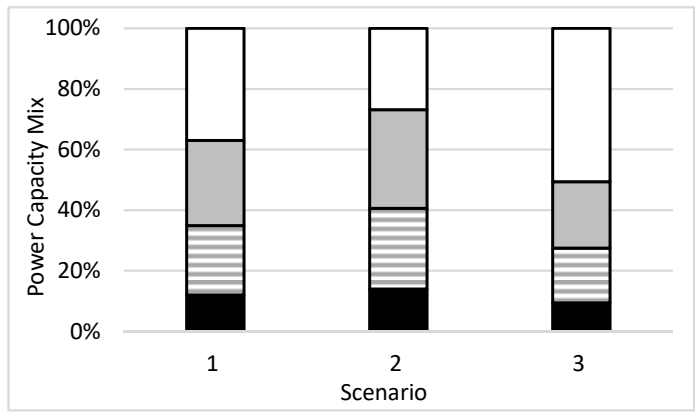

(b)

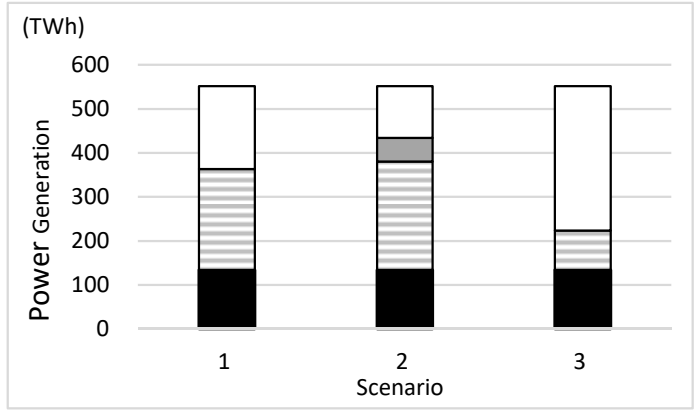

(c)

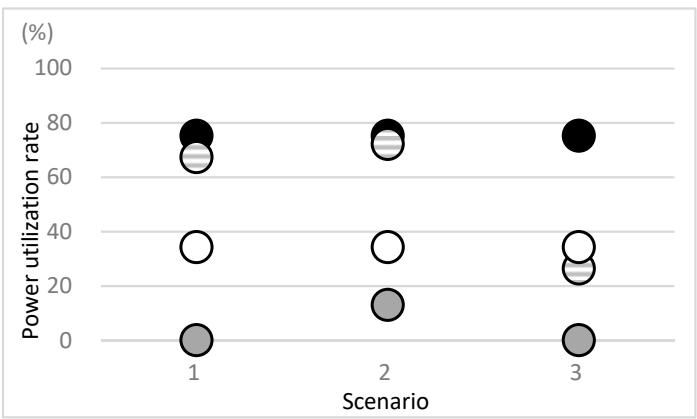

(d)

$\square$ RE $\square$ Gas $\boxminus$ Coal $\square$ Nuclear

Figure 5. Electricity supply in the Korean power market. (a) Capacity volume; (b) Capacity mix. (c) Generation volume; (d) Capacity utilization. 


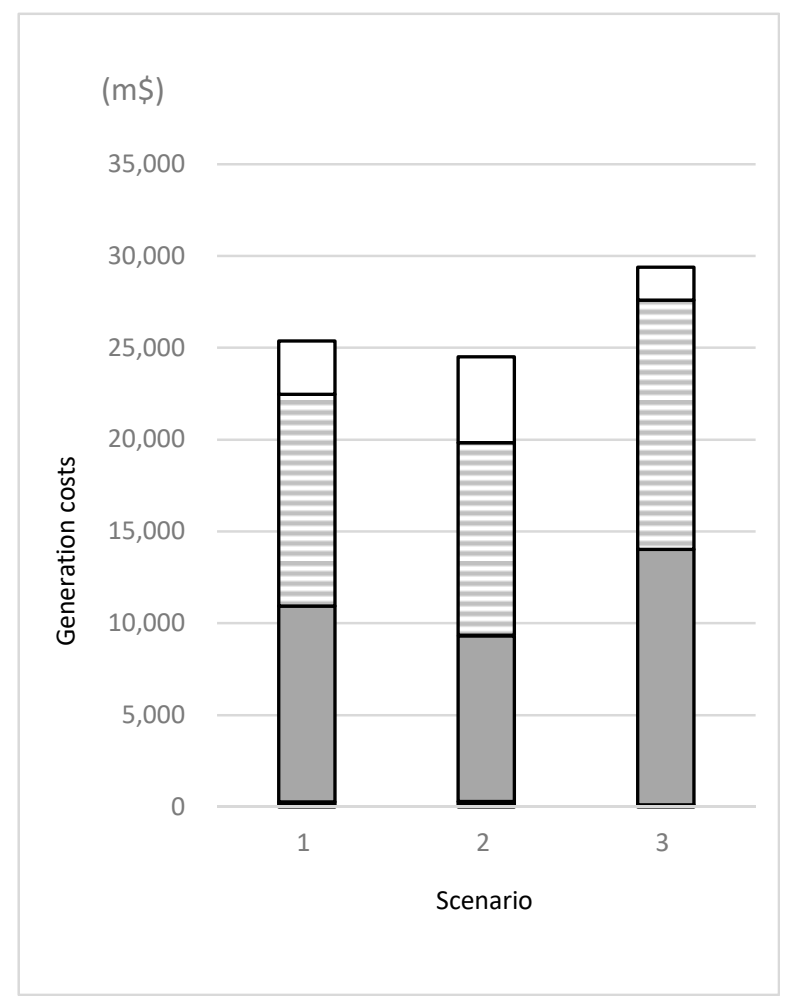

(a)

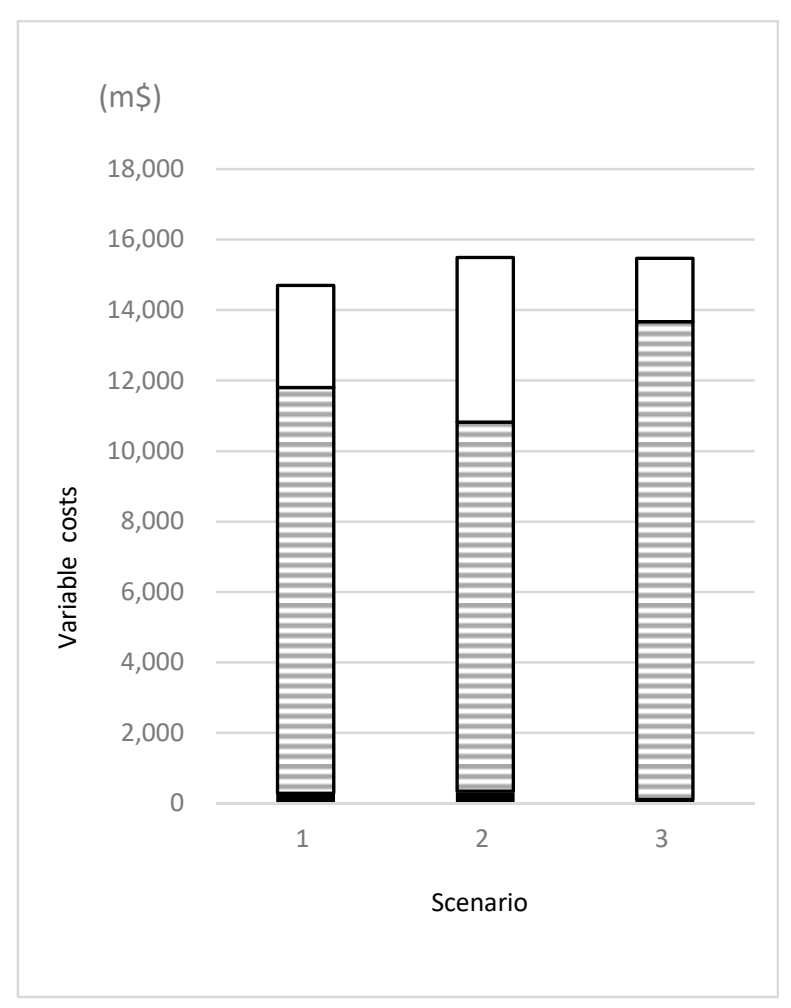

(b)

$\square$ Fuel costs $\square$ Fixed O\&M $\square$ Initial capital costs $\square$ Environmental costs

Figure 6. Costs in the Korean power market. (a) Generation cost; (b) Variable cost. 


\subsubsection{Market Value of RE}

Another impact of variable $R E$ was the increase in the market value, which was determined as the hourly weighted average price in the Korean power market. Since $R E$ has very low marginal cost, $R E$ reduces the market prices. As a result, their market value increases with $R E$ penetration. Figure 7 shows the market value with increasing shares in total RE consumption. In scenarios 1 and 2, rLCOE decreased with lower $R E$ penetration and it reached $\$ 28 / \mathrm{MWh}$ at $34 \%$ share and $\$ 26 / \mathrm{MWh}$ at $21 \%$ share, respectively. On the other hand, in scenarios $3, r L C O E$ of the power market was low and it was $\$ 27 / \mathrm{MWh}$ at $59 \%$ share because $R E$ was utilized during peak hours and had a limited impact on the market value. An increase in $R E$ penetration reduced the $r L C O E$ via a decrease in average fuel costs. Thus, the effect of variable $R E$ results in a difference between the average market price and the average fuel costs curtailed by $R E$ during peak hours. The increase in the market value of $R E$ affected the profitability of the power market in a positive way, which may imply a further reduction in the average market price for variable $R E$. That is, the market price decreased when the utilization of $R E$ increased. Conversely, in scenarios 1 and 2, LCOE increased with higher RE penetration and reached \$30/MWh at $34 \%$ share and $\$ 29 / \mathrm{MWh}$ at $21 \%$ share, respectively. In scenarios 3, LCOE was at its highest with $\$ 31 / \mathrm{MWh}$ at $59 \%$ share. The LCOE of scenario 1 was higher than that of scenario 2 , the main reason being that the indirect effect was not considered in the LCOE approach. Scenario 3 indicated that despite a higher proportion of RE, the total cost increased. However, the $r L C O E$ approach considered environmental and curtailment effects, and included other benefits when the NRE was not operating. The $S W$ was increased from $\$ 1 / \mathrm{MWh}$ at scenario 2 to $\$ 4 / \mathrm{MWh}$ at scenario 1 , and it was decreased to $\$ 3 / \mathrm{MWh}$ in scenario 3. According to these results, the market value of renewables increased in the Korean power market. Although the environmental costs had little impact on the electricity market, $F C$ was the largest single component that mainly determines the magnitude of total indirect effects. Therefore, our work showed three main results for $R E$. First, the largest cost driver at moderate shares was the reduction of $N R E$, even though the residual capacity mix optimally adapted to $R E$ deployment. Fortunately, these costs were saturated at higher market shares of $R E$. Second, with an increasing share of $R E$, overproduction costs occurred and grew rapidly. These costs drove the convex shape of indirect effects. Finally, $S W$ began to fall for high $R E$ shares. According to optimal shares, the $R E$ showed positive indirect effects due to a high FC of NRE.

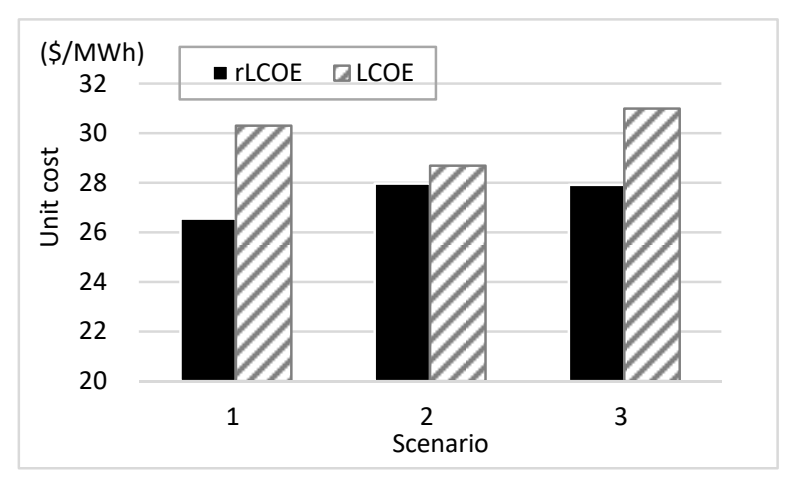

Figure 7. rLCOE and $L C O E$ results in each scenario.

\subsection{Sensitivity Analysis}

In this research, the two inputs could be varied in mathematical sensitivity analysis: (1) The FC and (2) the electricity demand. The market price and $R E$ capacity were varied according to the scenario assumption, thereby yielding one high-sensitivity and one low-sensitivity cost for each technology.

Figure 8 shows results of the sensitivity analysis with the fuel cost and electricity demand. It contained the indirect cost and the rLCOE values for the different combinations of costs for $R E$ and $N R E$, respectively. It also corresponded to the range of indirect costs derived from the sensitivity analysis. For the rLCOE values, each cost combination was shown as a varying line, where the rLCOE 
varied with fuel price. According to Figure 8a, all the combinations of each scenarios followed the same linear shape, where the sharp increase in $r L C O E$ came at a penetration level of scenario 1 with low $R E$ share. When the portion of $R E$ was low, the cost change was large because the effect of demand reduction was small. On the other hand, scenarios 1 and 3 show that the utilization rate of NRE, having a high variable cost, was kept low due to the high proportion of $R E$. Figure $8 \mathrm{~b}$ shows the results for $r L C O E$ from the sensitivity analysis of the electricity demand data input. These Figure $8 \mathrm{a}, \mathrm{b}$ show that the high $R E$ penetration represents the high curtailment of electricity demand, and low $N R E$ generation could reduce the $r L C O E$.

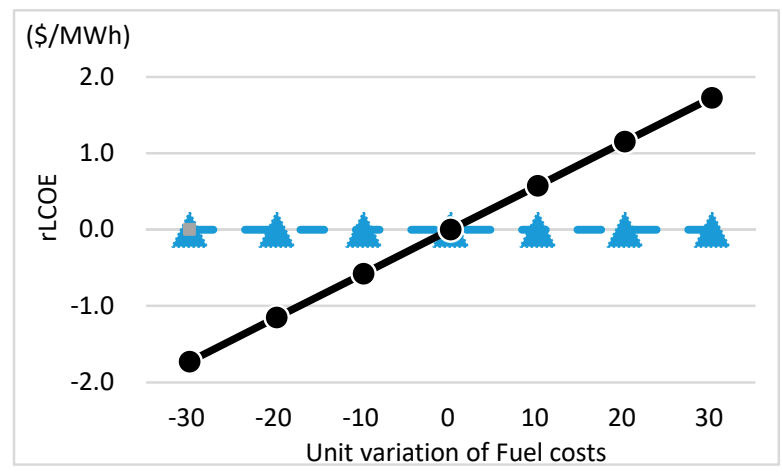

(a)

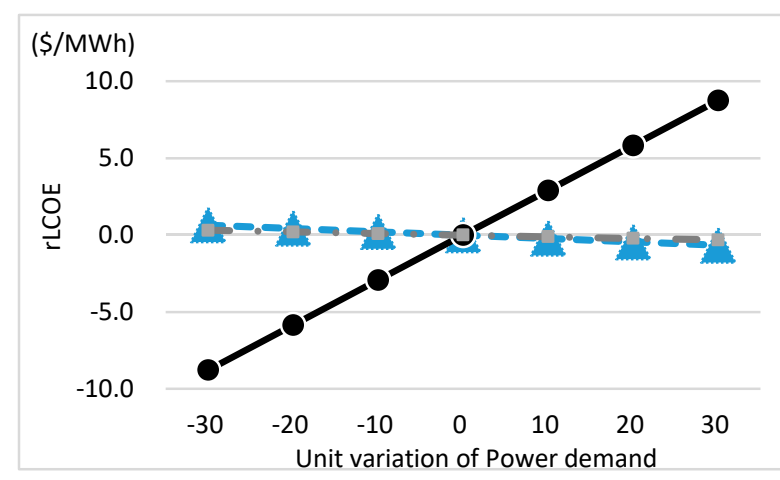

(b)

- $\Delta$ - - Scenario 1 -๑- Scenario 2 - ๑- Scenario 3

Figure 8. Sensitivity analysis. (a) Generation costs with variable fuel costs. (b) Generation costs with variable demand.

\section{Conclusions}

Policy makers generally use LCOE to compare power sources for energy conversion and review economic feasibility. However, $L C O E$ is not an ideal approach because it does not consider indirect costs. Comparing RE and NRE, LCOE tends to overestimate the economic viability of the power market whenever the share of $R E$ increases. In order to overcome these limitations, this research proposed a new $r L C O E$ approach, which was the sum of the LCOE and the marginal indirect costs per unit of electricity generation using the marginal cost of RE. Unlike the existing LCOE comparison, the rLCOE could determine the optimal power generation, which could facilitate a proper economic evaluation of $R E$. In order to standardize the $r L C O E$, it was necessary to define indirect costs mathematically based on economic theory. To validate the approach, a case study was performed on the existing electricity market in Korea. The following conclusions were drawn from this case study: 
(1) In the proposed approach, the indirect costs decreased with an increase in the market value of the power market as the proportion of RE increased. Using the rLCOE approach, the simulation results of scenarios 1, 2, indicate that the rLCOE decreased with lower RE penetration and increased in scenario 3 with a higher $R E$ share, respectively. On the other hand, LCOE increased with higher $R E$ penetration and scenarios 3 shows the highest $L C O E$. This indicates that an increase in $R E$ penetration reduced the $r L C O E$ via a decrease in the average fuel costs of curtailment effect.

(2) The $r L C O E$ and the total costs were significantly reduced by the RE supply, which could be an accelerator for $R E$ capacity expansion. It means that $R E$ capacity could be expanded until the $S W$ of $R E$ becomes stagnant. However, if the market value ceases to increase due to a high proportion of $R E$, no further installation will be necessary. Although the difference between $r L C O E$ and $L C O E$ was increased from scenario 2 to scenario 1 , the value was decreased in scenario 3 . Since indirect benefits decrease with a growing share of $R E$ in the market, it could be an economic barrier to deploying $R E$ with higher shares.

(3) Our work indicates that the largest cost driver in the electricity market is the reduction of NRE, even though the residual capacity mix optimally adapts to RE deployment. With an increasing share of $R E$, indirect costs occurred and grew rapidly. According to optimal shares in scenario 2, $R E$ shows positive indirect effects due to a high FC of NRE.

Therefore, the $r L C O E$ effectively resolved the challenge of integrating $R E$ and could guide policy makers in realizing a cost-efficient energy transformation with potentially high proportions of $R E$ in the electricity market. In the future we plan to extend our research design to include additional considerations such as changes in market price in response to the interaction of additional indirect effects.

Author Contributions: S.-H.H. proposed the main idea of this paper and M.-K.K. coordinated the proposed approach and thoroughly reviewed in the manuscript. H.-S.R. provided essential information and supported in manuscript preparation. All authors read and approved the manuscript.

Acknowledgments: This research was supported by the Chung-Ang University Research Scholarship Grants in 2019. This research was also supported by Basic Science Research Program through the National Research Foundation of Koera (NRF) funded by the Ministry of Education (2017R1D1A1B03029308).

Conflicts of Interest: The authors declare no conflict of interest.

\section{References}

1. Home-Ortiz, J.M.; Melgar-Dominguez, O.D.; Pourakbari-Kasmaei, M.; Mantovani, J.R.S. A stochastic mixed-integer convex programming model for long-term distribution system expansion planning considering greenhouse gas emission mitigation. Int. J. Electr. Power Energy Syst. 2019, 108, 86-95. [CrossRef]

2. Zeng, B.; Zhang, J.; Yang, X.; Wang, J.; Dong, J.; Zhang, Y. Integrated planning for transition to low-carbon distribution system with renewable energy generation and demand response. IEEE Trans. Power Syst. 2013, 29, 1153-1165. [CrossRef]

3. Pourakbari-Kasmaei, M.; Mantovani, J.R.S.; Rashidinejad, M.; Habibi, M.R.; Contreras, J. Carbon footprint allocation among consumers and transmission losses. In Proceedings of the 2017 IEEE International Conference on Environment and Electrical Engineering and 2017 IEEE Industrial and Commercial Power Systems Europe (EEEIC/I\&CPS Europe), Milan, Italy, 6-9 June 2017; pp. 1-6.

4. Cheng, Y.; Zhang, N.; Wang, Y.; Yang, J.; Kang, C.; Xia, Q. Modeling carbon emission flow in multiple energy systems. IEEE Trans. Smart Grid 2019, 10, 3562-3574. [CrossRef]

5. Cheng, Y.; Zhang, N.; Lu, Z.; Kang, C. Planning Multiple Energy Systems towards Low-Carbon Society: A Decentralized Approach. IEEE Trans. Smart Grid 2018. [CrossRef]

6. Energy Information Administration (EIA). Levelized Cost Levelized Avoided Cost of New Generation Resources in the Annual Energy Outlook, 2019; EIA: Washington, DC, USA, 2019.

7. Gough, M.; Lotfi, M.; Castro, R.; Madhlopa, A.; Khan, A.; Catalão, J.P. Urban Wind Resource Assessment: A Case Study on Cape Town. Energies 2019, 128, 1479. [CrossRef] 
8. Lucheroni, C.; Mari, C. Optimal integration of intermittent renewables: A system LCOE stochastic approach. Energies 2018, 113, 549. [CrossRef]

9. Paul, D.; Ela, E.; Kirby, B.; Milligan, M. Role of Energy Storage with Renewable Electricity Generation; Technical report NREL/TP-6A2-47187; National Renewable Energy Laboratory: Golden, CO, USA, 2010.

10. Kost, C.; Mayer, J.N.; Thomsen, J.; Hartmann, N.; Senkpiel, C.; Philipps, S.; Schlegl, T. Levelized cost of electricity renewable energy technologies. Fraunhofer Inst. Sol. Energy Syst. I.S.E. 2013, 144.

11. Merrick, J.H. On representation of temporal variability in electricity capacity planning models. Energy Econ. 2016, 59, 261-274. [CrossRef]

12. Reichenberg, L.; Hedenus, F.; Odenberger, M.; Johnsson, F. The marginal system LCOE of variable renewables-Evaluating high penetration levels of wind and solar in Europe. Energy 2018, 152, 914-924. [CrossRef]

13. Hirth, L.; Ueckerdt, F.; Edenhofer, O. Integration costs revisited-An economic framework for wind and solar variability. Renew. Energy 2015, 74, 925-939. [CrossRef]

14. Brouwer, A.S.; van den Broek, M.; Zappa, W.; Turkenburg, W.C.; Faaij, A. Least-cost options for integrating intermittent renewables in low-carbon power systems. Appl. Energy 2016, 161, 48-74. [CrossRef]

15. Frew, B.A.; Clark, K.; Bloom, A.P.; Milligan, M. Marginal Cost Pricing in a World Without Perfect Competition: Implications for Electricity Markets with High Shares of Low Marginal Cost Resources; National Renewable Energy Laboratory (NREL): Golden, CO, USA, 2017.

16. Chinmoy, L.; Iniyan, S.; Goic, R. Modeling wind power investments, policies and social benefits for deregulated electricity market-A review. Appl. Energy 2019, 242, 364-377. [CrossRef]

17. Rouwendal, J. Indirect effects in cost-benefit analysis. J. Benefit-Cost Anal. 2012, 3, 1-27. [CrossRef]

18. Mills, A. Changes in the Economic Value of Variable Generation at High Penetration Levels: A Pilot Case Study of California; Ernest Orlando Lawrence Berkeley National Laboratory: Berkeley, CA, USA, 2012.

19. Lamont, A.D. Assessing the long-term system value of intermittent electric generation technologies. Energy Econ. 2008, 30, 1208-1231. [CrossRef]

20. Liljas, B. How to calculate indirect costs in economic evaluations. Pharmacoeconomics 1998, 13, 1-7. [CrossRef]

21. Obi, M.; Jensen, S.M.; Ferris, J.B.; Bass, R.B. Calculation of levelized costs of electricity for various electrical energy storage systems. Renew. Sustain. Energy Rev. 2017, 67, 908-920. [CrossRef]

22. Ilas, A.; Ralon, P.; Rodriguez, A.; Taylor, M. Renewable Power Generation Costs in 2017; International Renewable Energy Agency (IRENA): Abu Dhabi, UAE, 2018.

23. Benes, K.J.; Augustin, C. Beyond LCOE: A simplified framework for assessing the full cost of electricity. Electr. J. 2016, 29, 48-54. [CrossRef]

24. Lew, D.; Brinkman, G.; Ibanez, E.; Hodge, B.M.; Hummon, M.; Florita, A.; Heaney, M. The Western Wind and Solar Integration Study Phase 2; National Renewable Energy Laboratory (NREL): Golden, CO, USA, 2013.

25. Pacione, M. Urban environmental quality and human wellbeing-a social geographical perspective. Landsc. Urban Plan. 2003, 65, 19-30. [CrossRef]

26. Conn, D. The evaluation of social costs and benefits. Ind. Mark. Manag. 1972, 2, 35-44. [CrossRef]

27. Fripp, M.; Wiser, R.H. Effects of temporal wind patterns on the value of wind-generated electricity in California and the northwest. IEEE Trans. Power Syst. 2008, 23, 477-485. [CrossRef]

28. Song, Y.H.; Kim, H.J.; Kim, S.W.; Jin, Y.G.; Yoon, Y.T. How to find a reasonable energy transition strategy in Korea? Quantitative analysis based on power market simulation. Energy Policy 2018, 119, 396-409. [CrossRef]

29. Christopher Frey, H.; Patil, S.R. Identification and review of sensitivity analysis methods. Risk Anal. 2002, 22, 553-578. [CrossRef]

30. The 8th Power Supply Plan in Korea. Available online: https://bit.ly/2VRvYU3 (accessed on 29 December 2017).

31. RE 3020 Plan in Korea. Available online: https://bit.ly/2Lug8ec (accessed on 20 December 2017).

32. Korea Power Exchange. Available online: https://www.kpx.or.kr (accessed on 12 December 2017).

33. Min, C.G.; Kim, M.K. Impact of the Complementarity between Variable Generation Resources and Load on the Flexibility of the Korean Power System. Energies 2017, 10, 1719. [CrossRef]

34. Ason, A. Price Reviews and Arbitrations in Asian LNG Markets; Oxford Institute for Energy Studies: Oxford, UK, 2019.

35. Energy Information Administration (EIA). World Energy Outlook. Available online: https://www.iea.org/weo/ (accessed on 1 January 2018). 
36. Vujić, J.; Antić, D.P.; Vukmirović, Z. Environmental impact and cost analysis of coal versus nuclear power: The US case. Energy 2012, 45, 31-42. [CrossRef]

37. Galetovic, A.; Muñoz, C.M. Wind, coal, and the cost of environmental externalities. Energy Policy 2013, 62, 1385-1391. [CrossRef]

38. Pazheri, F.R.; Othman, M.F.; Malik, N.H.; Safoora, O.K. Reduction in cost with limited emission at hybrid power plant in presence of renewable power. In Proceedings of the 2014 IEEE Global Humanitarian Technology Conference-South Asia Satellite (GHTC-SAS), Trivandrum, India, 26-27 September 2014; pp. 20-24.

39. Consonni, S.; Giugliano, M.; Grosso, M. Alternative strategies for energy recovery from municipal solid waste: Part B: Emission and cost estimates. Waste Manag. 2005, 25, 137-148. [CrossRef] [PubMed]

40. Park, J.; Bumsuk, K. An analysis of South Korea's energy transition policy with regards to offshore wind power development. Renew. Sustain. Energy Rev. 2019, 109, 71-84. [CrossRef]

(C) 2019 by the authors. Licensee MDPI, Basel, Switzerland. This article is an open access article distributed under the terms and conditions of the Creative Commons Attribution (CC BY) license (http://creativecommons.org/licenses/by/4.0/). 